references is generally aimed at giving a crow a test that should prove or disprove intelligence. This is an elusive goal and I am not convinced that crow intelligence is proven. However, the results are so amazing that it is impossible to deny that crows behave intelligently. In some ways they are surprisingly similar to humans.

\section{Antipredator Defenses in Birds and Mammals}

By Tim Caro. 2005. The University of Chicago Press, Chicago 60637. xv + 591 pages. U.S. \$95.00 Cloth. \$38.00 Paper.

Recently I read a report of Merlins hunting migrant chickadees as they flew out from a point along Lake Ontario. The falcons were capturing and eating the chickadees on the wing, and it made me ponder how defenseless the birds seemed, and the contrast with the shorebirds that Merlins are normally hunting in this location. To those of us who watch birds such events can often seem exciting and dramatic interludes in the birds' more usual activities, such as feeding. As such, they have generated over the years a host of anecdotal notes of the type above. But of course, defenses against predators are absolutely basic to an animal's life: without them there would be no feeding, or anything else. So the challenges of avoiding predation have become a fertile field of investigation.

Which brings me, finally, to this book, in which Tim Caro examines the bewildering range of mechanisms and strategies that enable mammals and birds to evade capture and death from the wide variety of predators that most animals face. Such is the multiplicity of all of these - prey species, defenses and predators - that any synthesis is daunting, yet Caro does a masterly job of mustering the relevant data from a huge and growing field, and rendering it into a coherent and lucid whole. The 87 pages of references alone attest to the encyclopedic character of the undertaking.

The book is divided into 13 chapters, with the first devoted largely to setting the stage, followed by 11 that trace the "predatory sequence" from traits that avoid detection, such as cryptic coloration, and behavioral mechanisms to avoid detection, through vigilance and prey signaling [both warning and of unprofitability], the benefits of grouping, and then physiological and morphological defenses, such as body size, quills, spines, antlers and the like. There is a chapter on nest defense, and one on mobbing and other group defenses, with chapter 12 devoted to "behaviors of last resort". Taken together, these provide a comprehensive overview of predator avoidance, with copious references to the literature, and tables and figures from relevant papers providing a useful complement to the text.
This is an ideal gift book. It is fun to get and read, but not the sort of book you normally buy for yourself.

ROY JOHN

2193 Emard Crescent, Beacon Hill North, Ottawa, Ontario K1J 6K5 Canada

Caro's formidable command of his subject is apparent throughout.

The thing that impressed me most about the book is its clarity. As a generalist with no more than a broad interest in the field, I had some trepidation about undertaking this review. The subject is, after all, at this level a technical one, and technical treatises can be relatively incomprehensible to the non-specialist. I need not have worried. While hardly light bedside reading, the entire text has a refreshing clarity and readability. From the preface onwards Caro clearly states what he is going to do, with the reasons why, and provides the appropriate references to those allied aspects of the field that he chooses not to cover. Then in each chapter he again defines the area he will cover, discusses it critically with copious examples, noting the weaknesses in our current understandings, and then provides a concise summary at the end.

Chapter 13, framing questions about antipredator defenses, brings the disparate threads of the previous chapters together, and focuses in on ten "pressing questions" which the author sees as particularly important at this time.

An appendix gives the scientific names of vertebrates mentioned, and each chapter has a delightful sketch of some aspect of animal behaviour that is appropriate to the text that follows. All the references that I checked were accurate, and the book is agreeably free of typographical mistakes. I am less enthusiastic about the indices, which are divided into "prey species index" and "subject index", and the former is further subdivided within the index itself. I've never been able to comprehend the rationale for split indices, but these seem adequate, if irritating.

This book is a major contribution to the literature on this subject. It is a "must" for anyone working in this or allied fields, an important reference text, and a comprehensive, stimulating and thought-provoking synthesis of a very important area of animal behaviour.

Clive E. Goodwin

1 Queen Street Suite 405, Cobourg, Ontario K9A 1M8 Canada 